\title{
A review on electric two wheelers
}

\author{
Syazwana Sapee ${ }^{1}$, Daing Mohamad Nafiz ${ }^{1, *}$, Ahmad Fitri Yusop ${ }^{1,2}$, Mohamad Firdaus \\ Basrawi $^{1}$, Azri Hizami Rasid ${ }^{1}$, Muhammad Hadi Hassan ${ }^{1}$ and Jiang Xiaoxia ${ }^{3}$ \\ ${ }^{1}$ Faculty of Mechanical Engineering, Universiti Malaysia Pahang, 26600 Pekan, Pahang, Malaysia, \\ ${ }^{2}$ Automotive Engineering Centre, Universiti Malaysia Pahang, 26600 Pekan, Pahang, Malaysia \\ ${ }^{3}$ School of Mechanical Engineering, Ningxia University, 750021 P. R. China
}

\begin{abstract}
South East Asian cities such as Kuala Lumpur, Jakarta and Bangkok rely heavily on motorcycles. A huge number of urban residents depend on motorcycles for all types of activities such as working, ridehailing and delivery services, going to school or leisure. According to Malaysia Automotive Association (MMA) statistics, there are about 13 million registered motorcycles in Malaysia as of August 2017. The pollutants that a four-stroke-engine $50 \mathrm{cc}$ motorcycle emits per kilometre are usually much higher than a 2-litre passenger car; 2.7 times higher for $\mathrm{CO}$ and 6.7 times higher for $\mathrm{HC}$ and NOx. Controlling excessive air pollution and emissions levels generated by the use of a motorcycle is one of the keys to improving air quality. Electric two-wheelers have been well adopted in Asia Pacific countries like China and Taiwan. This paper provides extensive review and analysis on development history, environmental and mobility impacts, challenge and limitation of electric two-wheelers from around the world and the potential of its emergence in Malaysia.
\end{abstract}

\section{Introduction}

Globalization and commercial interchange have led to a significant impact on transportation activities involving motorized vehicles worldwide [1]. According to Malaysia Automotive Association (MMA) statistics, there are about 13 million registered motorcycles in Malaysia as of August 2017[2]. Most of these motorcycles are powered by fossil fuel. The combustion of fossil fuels leads to smog and acid rain [3].

The traffic-related air pollutant cover mainly in cities area, generally they are sulfur oxides $\left(\mathrm{SO}_{\mathrm{X}}\right)$, carbon monoxide $(\mathrm{CO})$, particulate matter $(\mathrm{PM})$, and mono-nitrogen oxides $\left(\mathrm{NO}_{\mathrm{X}}\right)$ [3]. The pollutants that a four-stroke-engine $50 \mathrm{cc}$ motorcycle emits per kilometre are usually much higher than a 2-litre passenger car; 2.7 times higher for $\mathrm{CO}$ and 6.7 times higher for $\mathrm{HC}$ and $\mathrm{NO}_{\mathrm{X}}$ [4]. Various alternatives were applied to overcome this harmful emissions situation with the main focus to be minimized in routing models and also trading off environmental and economic goals [5, 6]. Controlling excessive air pollution and emissions levels generated by the use of a motorcycle is one of the keys to improving air quality. One of the promising strategies, and might be a good solution regarding the

\footnotetext{
*Corresponding author: daingnafiz@ump.edu.my
} 
environmental issues is the application of electric vehicles. Besides pollutions reduction, it also offers the potential for energy efficiency gains, in particular as an alternative to gasoline-power conventional vehicles $[1,7,8]$.

Correspondingly, this paper aims to provide extensive review and analysis on development history, development history, environmental and mobility impacts, challenge and limitation of electric two-wheelers around the world and look into the potential of its emergence in Malaysia.

\section{Development histories}

Starting from 2000, researchers seem to lay interest on electrical vehicle studies. This can be seen in the quantity of electrical vehicle-related publication as shown in figure 1, which identified to increase rapidly since a decade ago. Advanced on the efficiency of the electric vehicle and its flexibility of energy consumption are constantly established [1]. Asia Pacific region also has shown interest in electrical bikes research and development [9].

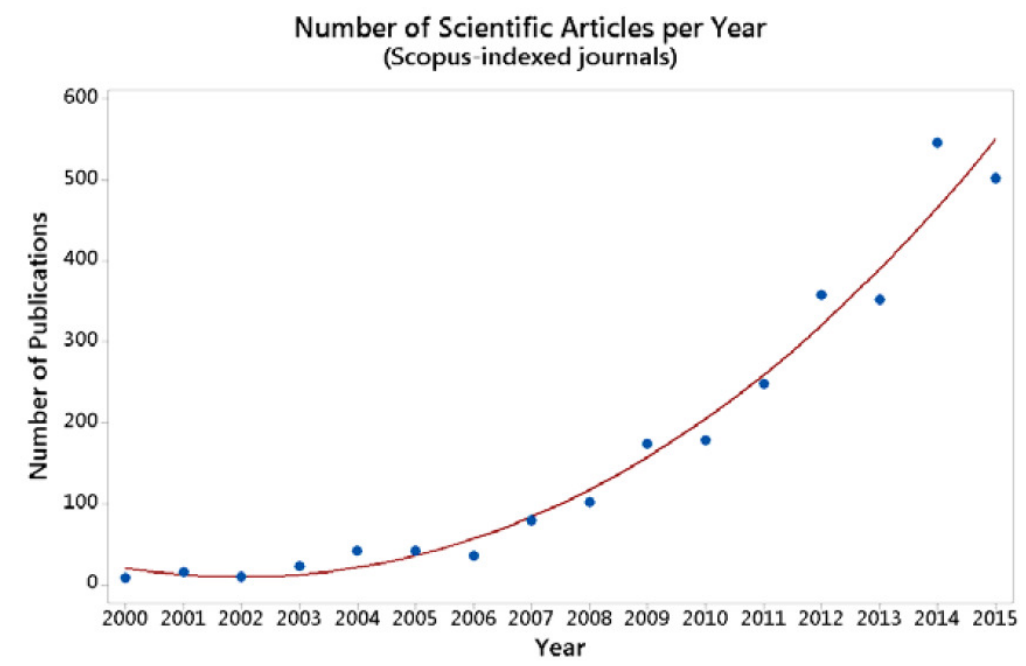

Fig. 1. A number of publication in Scopus-indexed journals regarding electric vehicle per year [1].

There have various types of electric vehicles. Four main categories of electrical vehicles are Hybrid Electric Vehicles (HEVs) which mainly consume gasoline but supported by small battery for combustion engine, Plug-in Hybrid Electric Vehicles (PHEVs) which generated by gasoline and electricity both independently, Battery Electric Vehicles (BEVs) which generated only by electricity, and Fuel Cell Electric Vehicles (FCEVs) which powered by hydrogen [9].

From a decade ago, Asia has been known as the world's leading in motorcycle population. In Asia alone, with quantity over 200 million units, Asian sales had covered $85 \%$ of motorcycle market sales worldwide. Constant growing with more than $10 \%$ increment annually had reported in most Asian countries [10]. It is one of the main choices of transportation in most compact cities in South East Asia like Kuala Lumpur, Jakarta and Bangkok.

Over $50 \%$ chose motorcycle as local transportation based on a study conducted in Asian countries, such as Thailand, Myanmar, Sri Lanka, India, China and Taiwan. Moreover, 90\% of vehicles registered in Vietnam are motorcycles [11]. The reliance on this method of transportation in the urban area is due to high traffic density, deficiency of parking spaces, narrow streets and to avoid traffic congestion. Motorcycles are preferred as a mode of 
transport in daily working basis, delivery services, personal or/and a passenger riding, short daily trip distance and even for leisure. Furthermore, its easy operation and maintenance, low cost, flexibility to road condition lead to the extensive use of motorcycles in urban areas [11].

Innovation in terms of battery capacity and charging technology has been improved over the year. These factors have occurred to be significant to electrical vehicle adaption. Nevertheless, the battery has limitation due to limited electricity capacity. Thus, an electrical vehicle is able to operate in short distance and time. Other than that, issues such as the high cost of the battery, the heavy weight of the battery pack, and long battery charging time, are the challenges of electrical vehicle adaption [12, 13]. Lithium-ion batteries usage is one great potential towards energy sustainability and carbon emission reduction [14].

\section{Environmental and mobility impacts}

In general, electrical vehicles offer a great reduction of air pollution such as $\mathrm{NO}_{\mathrm{X}}$, volatile organic compound (VOC), and $\mathrm{CO}$ [9]. In comparison, $\mathrm{CO}_{2}$ released by a diesel-consumed van was 54 times higher compared to an electric vehicle when travelled a mile [15]. A study in Taiwan shows emissions reduction on-road including $\mathrm{CO}, \mathrm{VOC}$, and $\mathrm{NO}_{\mathrm{X}}$ by $85 \%$, $79 \%$ and $27 \%$ respectively by replacing all light-duty vehicles with electrical vehicles [16]. In addition, the study also claims that overall emissions considering on-road and electricity generation could be reduced by electrical vehicle adaption [16].

Emission of $\mathrm{CO}_{2}$ also shown reduction with application of standard electrical vehicle and tricycle, down to $20 \%$ and $54 \%$ relatively compared to ICEVs emission production. The operator of the micro-consolidation centre, even assured that $\mathrm{CO}_{2}$ could be reduced by $62 \%$ [17]. This was supported by a couple of case studies conducted in New York the following year involving electric cargo cycle [18]. It reported that by using that vehicle, it has saved up to $8.3-13$ tons per year of $\mathrm{CO}_{2}$ emission and $1.6-2.5$ lbs per year of particulate matter. Electrical vehicle still is shown a reduction of $\mathrm{CO}_{2}$ even when consuming high intensity of electricity generated by coal power plants [9]. As an example, in China, where an electrical vehicle mostly benefits from coal-generated electricity, shows a reduction of $\mathrm{CO}_{2}$ by $20 \%$ using BEVs [19].

$\mathrm{O}_{3}$ is another gaseous pollutant that classified as ground-level or bad ozone. It is a secondary pollutant produced by chemical reaction of $\mathrm{NO}_{\mathrm{X}}$ and $\mathrm{VOC}$ in the presence of sunlight. It was reported that $\mathrm{O}_{3}$ transformation is also benefited from electrical vehicles $[16,20]$. For instance, in Taiwan, the average concentration of $\mathrm{O}_{3}$ showed a reduction in both urban areas and rural areas by $3 \%$ and $5 \%$ respectively [20].

Electrical vehicles or electric two-wheeler usage is a way to transfer air pollution from the road to electricity generation station [21]. Yet the environmental impact of its production and the electric power generation studies is scarce [22]. In general, $\mathrm{CO}_{2}$ emission produce by road transportation are 10 times compared to power plants'. Almost $35 \%$ of emission globally was contributed by vehicles exhaust that produced black carbon or "soot particles". Power plants on the other hand only contribute about $0.5 \%$ [23-25]. Yet, controlling charging time could significantly reduce particulate emission that produced by power plants [26]. Air pollution that produce from power plant emission, even they are mostly in rural areas, might significantly affect population exposure [27]. However, by using clean electricity sources, human health effects can be minimized. For example, electric vehicles that charged by renewable energy could reduce fatality 3700 to 6400 cases every year [28].

It was also proven that electric vehicle produces lower noise level compared to internal combustion engine vehicle, this helps on reducing noise pollution on road [17]. Electric 
motorcycle usage in both modern urban area and historical urban area with high traffic can decrease noise level by $59.9 \%$ to $82.6 \%$ [11].

\section{Challenges and limitations}

Yet again, two major challenges of adaption electrical two-wheelers or vehicles are its battery capacity and lack of battery charging station [1]. One of the main concerns for electric vehicle users is to plan their route, how far they could travel before a recharge is needed, due to dependent on battery energy [29]. This is because the electrical vehicle's travelled distance shorter than internal combustion engine vehicles [30]. It was estimated that the maximum driving range for a most electrical vehicle is about $150-250$ kilometres [31]. In addition, it must be recharged frequently. Hence, major issues of the development are the quantity and class of refuelling stations, the location of the stations, and their optimum capacity [1].

There are two choices when its batteries are drained, recharge or exchange them. For the matter of fact, a fast charging station and slow charging station both have their pros. For instance, at the fast charging station, the battery can quickly be recharged, sometimes in less than 5 minutes, but it also can shorten the batteries' life [32]. In opposition, a long time is required to recharge an electrical vehicle at a slow refuelling station, yet with lower cost. Level 1 or 2 slow charging stations, with capacity 110- $240 \mathrm{~V}$, needed 2 to 8 hours of waiting time to fully charge the vehicle batteries. In advance, Level 3 with $480 \mathrm{~V}$ capacities refuelling stations needed only 20 to 40 minutes to fully recharge a battery.

So it left with an exchange or swapping option. The main advantage of swapping a battery is the operation of exchanging a battery takes about 10 minutes, almost the same time needed for refuelling conventional internal combustion engine vehicle, and even faster at some recharging stations. With this option, the drained battery can be left and charge overnight, which the cost of charging is lower. It also maintains and expands the lifetime of the battery. The electrical vehicle users could also resume their journey right after swapping the battery and give them relief with full battery capacity [1].

There have several location models that have been suggested in order to locate optimal recharging station. They can be classified by node-based and flow-based [33]. One of the popular node-based models is a p-median model that has been proposed to locate conventional fuel or alternative fuel refuelling station by many scholars [34]. In opposition, the flow-based model has been studied more. It is due to demand by consumers since normally refuelling stations were visited based on traffic flow that the vehicles pass [35]. The flow-based mode was used to locate sufficient slow charging stations in beneficial for electric scooters owner, by considering their battery recharging efficiency and time [36].

\section{Conclusions}

We have reviewed the literature on the development history, environmental and mobility impacts, and the challenges and limitation for electrical vehicles adaption. The review can be useful for authorities and policymaker to plan strategies in developing electric vehicles technology in order to have green, sustainable and environment-friendly transportation.

The authors would like to express their deepest gratitude to the Ministry of Education (FRGS/1/2016/TK03/UMP/02/21 or RDU160139) and University Malaysia Pahang (RDU1603111) for their financial assistance for this project. 


\section{References}

1. A.A. Juan, C.A. Mendez, J. Faulin, J. de Armas, S.E. Grasman, Energies, 9, 86 (2016)

2. Paul Tan. Available from: https://paultan.org/2017/10/03/vehicle-registrations-inmalaysia-hit-28-2-million-units/, (2018, June 28)

3. M. Shahraeeni, S. Ahmed, K. Malek, B. Van Drimmelen, E. Kjeang, Journal of Natural Gas Science and Engineering, 24, 26 (2015)

4. Y.-C. Chiu, G.-H. Tzeng, Transportation Research Part D: Transport and Environment, 4, 127 (1999)

5. M. Figliozzi, Transportation Research Record: Journal of the Transportation Research Board, 1 (2010)

6. T. Bektaş, G. Laporte, Transportation Research Part B: Methodological, 45, 1232 (2011)

7. C.R. Cherry, J.X. Weinert, Y. Xinmiao, Transportation Research Part D: Transport and Environment, 14, 281 (2009)

8. A.J.C. Trappey, C. Trappey, C.T. Hsiao, J.J.R. Ou, S.J. Li, K.W.P. Chen, Energy Policy, 45, 510 (2012)

9. W.J. Requia, M. Mohamed, C.D. Higgins, A. Arain, M. Ferguson, Atmospheric Environment, 185, 64 (2018)

10. D. Meszler, International Council on Clean Transportation, Washington, DC, (2007)

11. N. Sheng, X. Zhou, Y. Zhou, Science of The Total Environment, 554-555, 73 (2016)

12. J.S. Gill, P. Bhavsar, M. Chowdhury, J. Johnson, J. Taiber, R. Fries, Procedia Computer Science, 32, 545 (2014)

13. Z. Li, M. Ouyang, Energy, 36, 5765 (2011)

14. G. Zubi, R. Dufo-López, M. Carvalho, G. Pasaoglu, Renewable and Sustainable Energy Reviews, 89, 292 (2018)

15. M.A. Figliozzi, Transportation research part E: logistics and transportation review, 46, $496(2010)$

16. N. Li, J.-P. Chen, I.-C. Tsai, Q. He, S.-Y. Chi, Y.-C. Lin, T.-M. Fu, Science of The Total Environment, 566, 919 (2016)

17. M. Browne, J. Allen, J. Leonardi, IATSS research, 35, 1 (2011)

18. A. Conway, P.-E. Fatisson, P. Eickemeyer, J. Cheng, D. Peters, in Proceedings of the 91st Transportation Research Board Annual Meeting, Washington, DC, USA. (2012).

19. H. Huo, Q. Zhang, F. Liu, K. He, Environmental science \& technology, 47, 1711 (2013)

20. G.L. Brinkman, P. Denholm, M.P. Hannigan, J.B. Milford, Environmental science \& technology, 44, 6256 (2010)

21. S. Ji, C.R. Cherry, W. Zhou, R. Sawhney, Y. Wu, S. Cai, S. Wang, J.D. Marshall, Environmental science \& technology, 49, 13912 (2015)

22. S. PELLETIER, O. JABALI, G. LAPORTE, Goods distribution with electric vehicles: Review and research perspectives. Montrál. 2014, Canada, 2014: Technical Report CIRRELT-2014-44, CIRRELT.

23. Z. Shen, J. Liu, L. Horowitz, D. Henze, S. Fan, D. Mauzerall, J.-T. Lin, S. Tao, Atmospheric Chemistry and Physics, 14, 6315 (2014)

24. W. Shen, W. Han, T.J. Wallington, Environmental science \& technology, 48, 7069 (2014)

25. R. Wang, Global Emission Inventory and Atmospheric Transport of Black Carbon: Evaluation of the Associated Exposure. Springer, (2015)

26. A. Weis, J.J. Michalek, P. Jaramillo, R. Lueken, Environmental science \& technology, 49, 5813 (2015) 
27. B.G. Nichols, K.M. Kockelman, M. Reiter, Transportation Research Part D: Transport and Environment, 34, 208 (2015)

28. M. Jacobson, W. Colella, D. Golden, Science, 308, 1901 (2005)

29. A.A. Juan, J. Goentzel, T. Bektaş, Applied Soft Computing, 21, 84 (2014)

30. M. Jaller, J. Holguín-Veras, S. Hodge, Transportation Research Record: Journal of the Transportation Research Board, 46 (2013)

31. W. Feng, M. Figliozzi, Transportation Research Part C: Emerging Technologies, 26, 135 (2013)

32. Y.-W. Wang, C.-R. Wang, Transportation Research Part E: Logistics and Transportation Review, 46, 791 (2010)

33. C. Upchurch, M. Kuby, Journal of Transport Geography, 18, 750 (2010)

34. M.F. Goodchild, V.T. Noronha, Spatial analysis and location-allocation models, 121 (1987)

35. M.J. Hodgson, Geographical Analysis, 22, 270 (1990)

36. Y.-W. Wang, International Journal of Sustainable Transportation, 5, 153 (2011) 